\title{
LA POPULARIZACIÓN DEL CANCIONERO: DE LOS GRANDES POETAS CANCIONERILES A LOS AUTORES GALANTES INTERMEDIOS (CON UN ESTUDIO DE CASO: ALONSO DE SALAYA)*
}

\author{
Laura Puerto Moro \\ Universidad Complutense de Madrid-IUMP \\ laurapuerto@pdi.ucm.es
}

\section{Preliminares}

Un análisis detenido del centenar de pliegos poéticos postincunables conservados que han llegado a ser inventariados en $2012^{1}$-al que hoy cabría restar dos ítems y añadir otros cinco $^{2}-$ permite aislar tres grandes líneas

\footnotetext{
*Agradecemos a la Profa. Mercedes Fernández Valladares la inestimable ayuda prestada para la elaboración de este trabajo, tanto por habernos facilitado materiales de difícil acceso como por sus valiosísimas observaciones sobre la datación y adscripción tipobibliográfica de determinados impresos. Este trabajo es fruto del Proyecto de Investigación «Literatura Popular Impresa en la Península Ibérica (s. $\mathrm{xVI}$ ): Estudio literario, editorial y socio-cultural comparativo de pliegos poéticos castellanos, catalanes y portugueses» (FFI2015-73439-JIN).

${ }^{1}$ Véase Laura Puerto Moro, «El universo del pliego poético postincunable (del despegue de la literatura popular impresa en castellano)», en eHumanista, 21 (2012), pp. 286-299. [En línea]. Enlace: $<$ https://www.ehumanista.ucsb.edu/sites/secure.lsit.ucsb.edu.span.d7_eh/files/sitefiles/ehumanista/volume21/9\%20eHumanista21.puerto.pdf $>$ [Consulta: 27/02/2020].

${ }^{2}$ Deberían retirarse del inventario de Puerto Moro los ítems 70 y 80 , correspondientes, respectivamente, al pliego teatral enciniano Égloga de Cristino y Febea, sin presencia de villancico de remate que permita su inclusión en un catálogo poético, y a RM 373, Glosa de esperança mía de Gonzalo de Gonzalo de Montalbán, sobre cuya necesidad de exclusión de la nómina de pliegos postincunables damos detenida cuenta más adelante en este mismo trabajo. Por el contrario, habría que añadir, a fecha de hoy, dos de los pliegos preservados en el Château de Chantilly, incorporados al Suplemento al Nuevo Diccionario en 2014: RM 128.5, Alonso de Cervantes, Glosa sobre las coplas de don Jorge Manrique, y RM 413.5, Rodrigo de Osorio, Adición hecha por Rodrigo Osorio sobre dos coplas que hallaron al señor don Jorge Manrique en el seno cuando lo mataron, así como el fragmento de pliego que ha llegado hasta nosotros correspondiente a RM 1179.8, más dos pliegos recentísimamente datados por Fernández Valladares: RM 16, La profecía de Pero Grullo (1516, anterior a agosto), y RM 601, El pleito de los judios con el perro
} 
temáticas confluyentes en el subcorpus que abarca contenidos propiamente literarios, entendiendo como tales los que se alejan de la solemnidad de la materia religiosa o político-propagandística -exclusiva de los cuadernos incunables ${ }^{3}$ - para satisfacer las necesidades de entretenimiento del público burgués que impulsa el nuevo mercado editorial. Se corresponden estas tres grandes líneas con: a) el Romancero, observándose una especial predilección por el llamado Romancero carolingio o pseudocarolingio, aunque no exclusiva; b) el motivo de la «befa del villano», que recorre medularmente los impresos de carácter dialógico-teatral, haciendo de pastores, comadres o rufianes irrisorias figuras ante las que un distanciado auditorio urbano vería especialmente colmadas sus ínfulas de superioridad; y c) la apropiación del mundo cancioneril, de forma especialmente ostensible en la que es su materia por antonomasia, la poesía amatoria, si bien encontramos también pliegos burlescos en los que se está realizando un claro pillaje sobre la sección correspondiente del Cancionero general ${ }^{4}$. Cabe añadir que, desde una perspectiva sociológica, resulta obvia la imposibilidad de separar las tendencias aquí apuntadas de los particulares rasgos idiosincráticos del público dinamizador del nuevo producto editorial del pliego: una pujante masa urbana de grado de alfabetización relativamente alto con respecto a épocas anteriores, ávida de diversión y con el modelo palaciego como referencia.

Establecido este marco general de aprehensión teórica, el presente trabajo pretende seguir adentrándose en el proceso de gestación y despegue del universo de la Literatura Popular Impresa en castellano desde la profundización en la tercera de las líneas enunciadas: su apropiación del mundo cancioneril, focalizándonos, específicamente, sobre la temática amatoria. Para ello nos centraremos, de entrada, en el estudio de los pliegos de este cariz de la etapa postincunable y en los autores cancioneriles de primera línea que los

de Alba (c. 1515-1520) (cfr. Mercedes Fernández Valladares, Laura Puerto Moro y Joan Mahiques Climent, Pliegos sueltos poéticos del siglo XVI en bibliotecas de Francia, México, FAH, 2020 [en prensa]). De acuerdo con la convención entre especialistas, las siglas RM hacen siempre referencia al número de registro del impreso en Antonio Rodríguez-Moñino, Nuevo Diccionario bibliográfico de pliegos sueltos poéticos (siglo XVI). Edición corregida y actualizada por Arthur L.-F. Askins y Víctor Infantes, Madrid y Mérida, Editorial Castalia y Editora Regional de Extremadura, 1997, más su Suplemento (Arthur L.-F. Askins y Víctor Infantes, Suplemento al Nuevo Diccionario de pliegos sueltos poéticos (siglo XVI) de Antonio Rodriguez-Moñino, ed. bibliográfica de Laura Puerto Moro, Vigo, Academia del Hispanismo, 2014).

${ }^{3} C f r$. Víctor Infantes, «Edición y realeza: Apuntes sobre los pliegos poéticos incunables», en Literatura hispánica, Reyes Católicos y descubrimiento (Actas del Congreso Internacional sobre Literatura hispánica en la época de los Reyes Católicos y el Descubrimiento), ed. de Manuel Criado de Val, Barcelona, PPU, 1989, pp. 85-98.

${ }^{4}$ Es el caso de RM 425, Coplas del Conde de Paredes a Juan poeta tornadizo, y RM 1, Aquí comiençan unas coplas de Juan Agraz a Juan Marmolejo, que reproducen, respectivamente los ff. 224r230v y 232r-234r de 11CG. Véase Puerto Moro, «El universo del pliego...», art. cit., asientos 54 y 55. 
firman, con atención especial a dos nombres de lugar propio en la andadura inicial del pliego poético: Juan del Encina y Garci Sánchez de Badajoz. En segundo lugar, nos adentraremos en una categoría de autores que va a tomar en gran medida el relevo de estos poetas cancioneriles a partir de la tercera década de siglo, si bien unos y otros conviven en el medio: hablamos de los denominados «autores galantes intermedios», categoría recentísimamente aprehendida por la crítica en la que se encuadran poetas ausentes de los Cancioneros, de exclusiva circulación en pliegos -hasta donde conocemos-, pero muy próximos a la estética cancioneril en sus composiciones amorosas, que entrelazan con piezas burlescas y, sobre todo, con la glosa de romances, llegándose a convertir en auténticos puentes entre la «alta» y «baja» cultu$\mathrm{ra}^{5}$. Tratándose de autores básicamente por estudiar, este artículo ahonda en sus claves compositivas desde un caso concreto y muy representativo, el de Alonso de Salaya.

Abordaremos el proceso de popularización de la poesía cortesano-amorosa en un estudio que bascula, por tanto, desde la atención a la presencia de los grandes nombres cancioneriles en pliegos postincunables hasta la posterior asimilación y difusión del Cancionero por los llamados «autores galantes intermedios». No se trata ahora de constatar que el pliego poético fue un canal más de difusión de la poesía cancioneril, hecho bien conocido por la crítica desde hace tiempo, sino de indagar en el cómo y de qué manera se produce el trasvase.

\section{Pliegos amatorios postincunables y grandes nombres cancioneriles: Sán- chez de Badajoz y Juan del Encina}

De la totalidad de ciento tres pliegos poéticos conservados que podemos adscribir a la etapa postincunable a fecha de hoy, nueve transmiten poesía amatorio-cancioneril, lo que equivale a la exigua cifra de un $8,7 \%$ del corpus, porcentaje que, no obstante, necesariamente hay que contrastar con el $13,7 \%$ de pliegos amatorio-cancioneriles -cuatro de un corpus de veintinueve- recogidos en un volumen facticio de pliegos poéticos y teatrales preservado en la Biblioteca Nacional de Francia bajo signatura Rés. Yg. 86-112, procedente de la biblioteca decimonónica de M. Jean-Jacques De Bure, que hubo de ser reunido en tempranas fechas, tal vez a principios del s. XVI por el propio Hernando Colón y cuya totalidad de cuadernos pertenecen a la etapa

${ }^{5} \mathrm{Cfr}$. Laura Puerto Moro, «Sobre "autores galantes intermedios”. De la poesía amatoria cancioneril a la literatura popular impresa», en Pragmática y metodologías para el estudio de la poesía medieval, coord. por Josep Lluís Martos y Natalia A. Mangas, Alicante, Universidad de Alicante, 2019, pp. 255-266. 
postincunable, con lo que probablemente habría de tomarse como un indicio mucho más veraz del surtido real del mercado del pliego en la época ${ }^{6}$.

Sin olvidar el grado de arbitrariedad de ese conjunto de nueve ítems, no puede ser en absoluto casual, sin embargo, que en su totalidad transmitan textos de previa difusión en los principales cancioneros, vinculándose con cuatro nombres bien conocidos en ellos: Garci Sánchez de Badajoz (RM 43, RM 44.5, RM 45 [+46] y RM 47), Juan del Encina (RM 182, RM 183 y RM 175.5), Costana (RM 156) y Quirós (RM 460). Implica el dato la clara dependencia de estos primeros pliegos amatorios con respecto a las compilaciones poéticas en boga, un hecho ante el que no podemos dejar de reflexionar sobre la influencia que pudo ejercer la publicación del Cancionero general (1511) en el incipiente mercado del pliego, argüida desde el clásico estudio de Norton y Wilson, quienes juzgaron la compilación de Del Castillo como potente estímulo e inagotable mina para nuestras menudencias ${ }^{7}$. No ha de olvidarse en esta reflexión, sin embargo, que el impulso que tomó el nuevo producto editorial solo a partir de la segunda década del Quinientos sería inseparable de la superación de la crisis de la imprenta española de la década inaugural de siglo ${ }^{8}$, por un lado, y, por otro, que el cotejo de testimonios descarta el Cancionero general como fuente inmediata de la mayoría de los pliegos del corpus considerado que comparten textos con la compilación de Del Castillo, al menos de los de Garci Sánchez de Badajoz y del correspondiente a Quirós9.

\footnotetext{
${ }^{6}$ Se reproducen todos los pliegos poéticos que integran este volumen en Fernández Valladares, Puerto Moro y Mahiques Climent, ob. cit.

${ }^{7}$ Cfr. Frederick J. Norton y Edward M. Wilson, Two Spanish verse chap-books. Romance de Amadis (c. 1515-1519), Juizio hallado y trobado (c. 1510), Cambridge, University Press, 1969, pp. 8-9. Sitúa en sus dimensiones exactas la vinculación entre pliegos quinientistas y Cancionero general Mario Garvin, «(Re)contextualización de materiales cancioneriles en pliegos sueltos quinientistas», en Convivio: estudios sobre la poesía de cancionero, ed. de Vicenç Beltran y Juan Paredes, Granada, Universidad de Granada, pp. 363-374.

${ }^{8}$ Esta fue especialmente acusada en el que sería en el futuro un gran centro productor de pliegos como Burgos. Véase el magno trabajo de Mercedes Fernández Valladares, La imprenta en Burgos (1500-1601), Madrid, Arco/Libros, 2005, vol. I, pp. 130-132, así como el estudio fundamental sobre la crisis generalizada de la imprenta a principios de siglo, que afectó también fuera del reino de Castilla a focos impresorios como el valenciano, de Philippe Berger, «La crisis de 1506-1509. Crónica de una quiebra anunciada», en La memoria de los libros. Estudios sobre la historia del escrito y de la lectura en Europa y América, dir. de Pedro M. Cátedra \& María Luisa López Vidriero, ed. de María Isabel de Páiz Hernández, Salamanca, 2004, vol. I, pp. 393-403.

${ }^{9}$ Ya Infantes puso de manifiesto la no dependencia del testimonio de Las leciones de Job en caso de amores recogido en RM 44.5 con respecto al Cancionero general 1511 (cfr. Víctor Infantes, «Las leciones de Job en caso de amores. Trobadas por Garci Sánchez de Badajoz», en Un volumen facticio de raros post-incunables españoles, coord. por Julián Martín Abad, Toledo, Antonio Pareja, 1999, pp. 89-91). Tampoco ninguna de las composiciones de Badajoz que se recogen en RM 45[+46] y RM 47, Maldiciones dichas clara escura ni su Infierno de amadores transmitido por RM 43 se vinculan con el Cancionero general ni con las otras compilaciones poéticas en las que nos ha llegado la obra de este autor,
} 
Descartado el pillaje de esos cuadernos en concreto sobre el Cancionero general, no nos cabe la menor duda, sin embargo, de que el saqueo de las grandes compilaciones poéticas por el mercado del pliego fue práctica común en la época, con ejemplos tan meridianamente claros como el que aporta, dentro del conjunto aquí acotado, RM 183, Perqué de amores de Juan del Encina, impreso por Jacobo Cromberger $c$. 1511-1515, que reproduce los ff. LXXXIv-LXXXIIv del Cancionero de 1496 -o de alguna de sus sucesivas ediciones ${ }^{10}$-. El pliego, en consonancia con la explotación del filón que Cromberger pareció hallar en la obra del salmantino ${ }^{11}$, se ajusta perfectamente en su extensión de dos hojas in $-4^{\circ}$ a los referidos folios del Cancionero enciniano, sin adición ni supresión de ningún verso, y sin que el impresor se haya preocupado ni tan siquiera de presentarlo bajo un encabezamiento que refleje las dos composiciones que en él se integran ${ }^{12}$. De la misma manera, también inadecuada resulta la rúbrica de los impresos gemelos RM 47 y RM 45 [+46], salidos, respectivamente del taller sevillano de los Cromberger $c$. 1511-15 y del toledano de Villaquirán $c$. 1515: «Las maldiciones dichas clara escura del mismo garcisanches de badajoz comiençan de esta manera» ${ }^{13}$, donde la presentación «del mismo» denuncia con claridad la dependencia del cuaderno con respecto a un conjunto poético mayor en el que se incluirían varias obras de Sánchez de Badajoz, si bien en este caso no hemos podido identificar la fuente.

Obvio es que frente a la intensa proliferación en pliegos a partir de los años veinte del s. XVI de la categoría autorial correspondiente a los «poetas galantes intermedios», según estudiaremos y detallaremos más adelante,

según queda probado en Fernández Valladares, Puerto Moro y Mahiques Climent, ob. cit. Igualmente, un primer cotejo entre la Metáfora en metros de Quirós de RM 460 y el texto correspondiente del Cancionero general demuestra que nos encontramos ante dos versiones claramente divergentes, divergencia que atañe particularmente a la última parte de la composición. Sería necesario, por fin, un estudio detenido de microvariantes para establecer la relación exacta entre RM 156, encabezado por el Conjuro de amor de Costana, y el Cancionero general.

${ }^{10}$ El facsímil del Cancionero de 1496 (Cancionero de las obras de Juan del enzina, Salamanca, 1496. Reproducido en facsímile por la Real Academia Española en Madrid, Tipografía de la Revista de Archivos, Bibliotecas y Museos, 1928) puede consultarse en red en la siguiente dirección, dependiente de la Biblioteca virtual Miguel de Cervantes: $<\mathrm{http} / /$ www.cervantesvirtual.com/obra-visor/cancionero-dejuan-del-encina-primera-edicion-1496--0/html/> [Consulta: 27/02/2020].

${ }^{11}$ Según pusieron tempranamente de manifiesto tempranamente Norton y Wilson, ob. cit., p. 9.

${ }^{12}$ Lleva por encabezamiento el pliego «Perqué de amores hecho por Juan del Enzina: requestando a una gentil mujer», rúbrica que solo se corresponde con la primera de las composiciones en él recogidas, siendo la segunda una «Justa de amores hecha por Juan del Enzina a una doncella que mucho le penava la qual de su pena quiso dolerse».

${ }^{13} \mathrm{~A}$ no ser que explícitamente se indique de otra manera, todas las dataciones y adscripciones tipobibliográficas de los pliegos contempladas en este trabajo se hallan recogidas en el Nuevo Diccionario bibliográfico de pliegos sueltos poéticos (s. XVI) y en su Suplemento, obras ambas citadas con anterioridad. 
estos primeros pliegos poéticos amatorios se alimentan de las composiciones disponibles y ya existentes generadas por los grandes nombres del Cancionero. Ello, a través, inicialmente, de una selección textual en la que domina el largo poema amoroso - generalmente un decir, aunque no falta la modalidad del perqué o el extenso poema heterométrico- en función de encabezamiento de pliego y reclamo editorial, idiosincráticamente ligado a la temprana cronología aquí manejada, y en contraste con la que habrá de consolidarse como predilección del medio por los géneros amorosos «menores»: fundamentalmente villancicos, pero también canciones y romances, que, ubicados por lo general en posición de interior de impreso o directamente de remate -así, muchos villancicos encinianos-, se combinan con piezas dialógico-teatrales, o burlescas, o con otros romances y glosas de romances a lo largo de toda la centuria, pero en particular durante su primera mitad. Solo romperían tal tendencia compilaciones de piezas menores en la estela del postincunable enciniano RM 182, Muchas maneras de coplas e villancicos con el juyzio de Juan del Enzina (Sevilla: Cromberger, c. 1511-15) y el pliego con él emparentado RM 175.5, Aqui comienzan muchas maneras de coplas e villancicos con un juyzio de Juan del Enzina (probable impreso italiano) ${ }^{14}$.

Dejando a un lado RM 182 y RM 175.5, insistimos en que es el largo poema amatorio cancioneril el que funciona como reclamo y apertura de la mayoría de pliegos postincunables de esta índole, siendo, sin embargo, muy infrecuente su presencia en el ámbito más allá del primer tercio del s. XVI, arco temporal parejo al momento álgido en la difusión y ampliación de público del Cancionero del que dan buena cuenta las sucesivas reediciones y continuaciones de la compilación de Del Castillo. Encabezan decires amorosos los pliegos de Garci Sánchez de Badajoz: RM 43, Infierno de amadores (Sevilla: Cromberger, c. 1511-15) y los mencionados RM 47 y RM 45 [+46], Maldiciones dichas claro escura, así como RM 156, Conjuro de amor de Costana (Burgos: Basilea, c. 1515-17, o Melgar, c. 1518-19) -reeditado en los años

\footnotetext{
${ }^{14}$ Julián Martín Abad, en su Post-incunables ibéricos, Madrid, Ollero \& Ramos, 2001, n. ${ }^{\circ} 1089$, mantiene para este pliego la adscripción de «Sevilla, Jacobo Cromberger, c. 1511-1515» propuesta inicialmente por Askins, si bien afirma: «En el último instante de la corrección de pruebas de este repertorio, Víctor Infantes, interesado como yo en este pliego, ha logrado una reproducción que me ha dado a conocer inmediatamente. Dicha reproducción [...] no permite identificar con seguridad los tipos empleados, obligándome a mantener la atribución indicada, aunque pienso (y no creo equivocarme) que su presencia no es pertinente dentro de este repertorio». Fernández Valladares, sin descartar que el impreso pueda ser post-incunable, se decanta, sin embargo, por el origen italiano del cuaderno, salido tal vez del taller de Antonio Blado. Nos remitimos a Mercedes Fernández Valladares, «Más identificaciones de pie de imprenta para pliegos poéticos del siglo XVI sin datos» (trabajo en elaboración).
} 
treinta (RM $\left.157^{15}\right)$-, mientras que son perqués la Metáfora en metros de Quirós que abre RM 460 (Toledo: Villaquirán, c. 1515) y el ya referido Perqué de amores de Encina con el que principia RM 183, relación que se completa con el amplio poema heterométrico de Badajoz recogido en RM 44.5, Las lecciones de Job en caso de amores, de adscripción tipobibliográfica discutida ${ }^{16}$.

Si el largo decir amoroso es la apertura por excelencia del pliego cancioneril más característico de los inicios del s. XVI, el autor que sin duda destaca en ellos es Garci Sánchez de Badajoz. Prueba de su popularidad son los mencionados y madrugadores pliegos gemelos RM 47 y RM 45 [+46], Maldiciones dichas clara escura, salidos respectivamente, según quedó expuesto, $c$. 151115 y c. 1515 de dos grandes centros productores de estas menudencias en la época: el taller de los Cromberger en Sevilla y el de Villaquirán en Toledo. También al tercer quinquenio del s. XVI y también al taller de los Cromberger pertenece el que sabemos que fue ampliamente conocido en la época texto del Infierno de amadores, cuyo incremento de la nómina de damnificados por el amor con respecto a los testimonios en Cancioneros y esencial ajuste del número de versos a las prototípicas cuatro hojas de extensión del cuaderno sería un buen ejemplo de la práctica de la amplificatio en pliegos y de los procesos que intervienen en la popularización del texto ${ }^{17}$. Por fin, aunque no se trata propiamente de un decir, hemos de completar el conjunto con la más que probable circulación en pliegos postincunables de Las leciones de Job en caso de amores trovadas por Garci Sanches, a pesar de que no ha sido precisada con exactitud la adscripción tipobibliográfica del impreso en el que nos

${ }^{15}$ En Fernández Valladares, ob. cit., asiento n. ${ }^{\circ}$ 360, se propone para RM 157 la adscripción tipobibliográfica de «Burgos, Juan de Junta, c. 1540-1543»; sin embargo, en Fernández Valladares y Mendoza Díaz-Maroto, se corrige la datación al considerar que el pliego probablemente habría formado parte de un volumen facticio colombino de pliegos poéticos y teatrales, lo que implica que la cronología del impreso no puede extenderse más allá de julio de 1539, fecha en la que fallece Hernando Colón. Cfr. Mercedes Fernández Valladares y Francisco Mendoza Díaz-Maroto, «Los impresos burgaleses de Don Hernando Colón: algunas concordancias y rastros de pliegos sueltos colombinos (con la noticia de una nueva edición del cuentecillo del Rústico labrador)», en Homenaje a Klaus Wagner, ed. de Piedad Bolaños et al., Sevilla, Universidad de Sevilla, 2007, p. 221.

${ }^{16}$ Nos detenemos en el complejo asunto de la adscripción tipobibliográfica de este pliego en una extensa nota al pie incluida más adelante.

${ }^{17}$ Estos datos son puestos de relieve, con mayor lujo de detalles, en el estudio específico que de RM 43 se realiza en Fernández Valladares, Puerto Moro y Mahiques Climent, ob. cit. Otro buen ejemplo de amplificatio en pliegos -si bien no utiliza esta terminología- es el ofrecido por Massimiliano Andreoli, «Quirós nei pliegos sueltos: studio delle varianti macrotestuali», en Filologia dei testi a stampa (area iberica), coord. de Patrizia Botta, Módena, Mucchi Ed., 2005, pp. 421-428. 
ha llegado esta obra, RM $44.5^{18}$, donde la pieza de Badajoz es rematada por dos villancicos anónimos de amplia difusión ${ }^{19}$.

Sin duda, la temprana transmisión en pliegos de Garci Sánchez contribuyó a-o se retroalimentó de- el auténtico «espaldarazo al poeta» que, en palabras de Parrilla ${ }^{20}$, supuso el importantísimo incremento de su obra en la edición de 1514 del Cancionero general, lo que nos hace insistir en las infinitas interrelaciones entre primeros pliegos y cancioneros, si bien no puede perderse de vista que ninguno de los cuadernos arriba nombrados bebe directamente de la compilación de Castillo. Tal vez no resulte casualidad, por otra parte, que sea Badajoz el representante por excelencia del pliego cancioneril prototípico de la etapa postincunable si tenemos en cuenta que su figura va a ser recordada por las posteriores generaciones literarias como la más destacada entre los poetas de Cancionero, al margen de la cuasi leyenda que rodeó su vida ${ }^{21}$.

Yendo más allá del periodo postincunable, de la acogida en el medio de Garci Sánchez es prueba la amplísima transmisión de su «romance»-así rubricado siempre, aunque se trata de un perqué- «Caminando por mis males», presente hasta en nueve pliegos de la primera mitad del s. XVI, la mayoría adscritos al primer tercio del Quinientos, siendo varios de ellos portadores, además, de piezas romanceriles del Cancionero general, sin que falte en esta difusión ni la glosa sin vinculación explícita con nuestro autor ni su integración

\footnotetext{
${ }^{18}$ En un principio, y tentativamente, RM 44.5 fue adscrito por Martín Abad a «¿Burgos, Fadrique Biel de Basilea, $c .1516$ ?» y así quedó recogido en Martín Abad, ob. cit., asiento n..$^{\circ} 1389$; una adscripción que rebate Fernández Valladares, $o b$. cit., pp. 1308-1309, quien considera como posibles líneas de indagación sobre su origen bien la imprenta sevillana de los Cromberger, en relación con su tipo 14 Gótico 72-74, siendo insostenible en este caso que el pliego sea anterior a 1520, bien alguno de los talleres de Arnao Guillén de Brocar, sin descartar la imprenta barcelonesa de Wendelin Rosenhayer. En el caso de que el pliego fuese crombergiano, habría que rechazar su condición de postincunable, sin embargo, lo dudoso de ello, por una parte, y, por otra, la circunstancia más que plausible de que circulara una edición postincunable en pliegos de las Leciones de Job en caso de amores, aunque esta no se correspondiese con la conocida, de acuerdo con el momento de máximo apogeo de la difusión de Badajoz en pliegos, nos llevan a una actitud conservadora y a seguir incluyendo RM 44.5 dentro de los pliegos postincunables considerados.

${ }^{19}$ Son estos los villancicos anónimos que comienzan «No ay plazer en esta vida / sin dolor» y «Mal de muchos no consuela / mi dolor», recogidos también, y siempre conjuntamente, en el impreso colombino RM 176, Coplas de la muerte cómo llama a un poderoso cavallero y en los pliegos gemelos portadores de las Coplas sobre lo acaescido en la Sierra Bermeja RM 827 (Sevilla: Cromberger, c. 1516-1526) y RM 837 (Sevilla: Cromberger, c. 1511-1515). El primero de los villancicos figura, asimismo, en RM 885, Glosa del romance que dize Afuera, afuera, Rodrigo (Burgos, Juan o Felipe de Junta, c. 1550-1565).

${ }^{20}$ Carmen Parrilla, «Garci Sánchez de Badajoz y la propulsión del "Cancionero General”», en Letras, 65-66 (2012), pp. 65-88, p. 67.

${ }^{21}$ Una clara síntesis de su vida y obra es la ofrecida por Antonio Chas Aguión en el Diccionario Biográfico de la Real Academia de la Historia [En línea]. Enlace: <http://dbe.rah.es/biografias/6349/garcisanchez-de-badajoz $>$ [Consulta: 28/02/2020]. Para más detalle, puede consultarse el clásico estudio sobre el poeta de Patrick Gallagher, The life and works of Garci Sanchez de Badajoz, Londres, Tamesis Books, 1968, pp. 3-44, donde recoge, además de los escasos datos biográficos que poseemos sobre el autor, gran parte del anecdotario áureo en torno a él.
} 
en unas coplas de disparates, lo que nos da idea del éxito de la pieza ${ }^{22}$. Como enorme fue también el éxito de su villancico «De mi dicha no se espera», presente, en este caso siempre de manera anónima, hasta en siete pliegos quinientistas, cinco de ellos encabezados por Alonso de Alcaudete y, entre estos, cuatro correspondientes a sucesivas ediciones de la Glosa sobre el romance que dicen Tres cortes armara el rey que se extienden en la imprenta burgalesa -fundamentalmente- desde al menos los años treinta hasta finales del s. $\mathrm{XVI}^{23}$. De cancionerillos más que de pliegos poéticos propiamente dichos habríamos de tildar los impresos RM 369.5, Cancionero de Juan de Molina (Salamanca, 1527) y RM 870, Espejo de enamorados (Sevilla: Estacio Carpintero, década de los 40), donde se transmite el villancico «Lo que queda es lo seguro», anónimamente en el primero, mientras que en el segundo acompaña al también villancico de Badajoz «Secaronme los pesares», recogido, igualmente, en la miscelánea del pliego colombino RM 667, Aquí comiençan muchas maneras de coplas y villancicos de muchos auctores, y contrahecho a lo divino en RM 932, Las siete palabras que dixo nuestro Señor (Toledo, ¿1525-1530?). Pasando a sus canciones, figura «Si por caso yo viviere» entre las incluidas anónimamente en la Égloga de Plácida y Vitoriano (RM 178, Burgos: Melgar, $c .1518-1520)$, a la par que la que principia «Tan contento estoy de vos» alcanza los años setenta de la centuria mediante su integración anónima y como remate de pliego en el de Juan Boravalias Mayayo, Romance de Leandro (RM 63, Granada: Hugo de Mena, 1570). Añadamos, entre las

${ }^{22} \mathrm{El}$ romance es recogido con la correspondiente atribución a Garci Sánchez de Badajoz en RM 653, Romance de Melisenda (Burgos: Basilea o Melgar, c. 1515-1519); RM 1007, Romance de Durandarte (Burgos: Melgar, c. 1520); RM 1011, Romance de la Mora Moraima (Sevilla: Cromberger, c. 1520); y RM 870, Espejo de enamorados o Guirnalda Esmaltada (Sevilla: Cromberger, c. 1535-1540). Glosado y sin vinculación explícita con nuestro autor lo hallamos en los pliegos gemelos burgaleses RM 686 y 685, Aqui comienzan tres romances, impresos, respectivamente, por Alonso de Melgar, $c .1525$ y Juan de Junta, $c$. 1535-1540; así como en RM 689 (Sevilla: Cromberger, c. 1520) y en RM 688 (sin adscripción tipobibliográfica), Aqui comienzan tres romances, pliegos editorialmente emparentados y entre los que solo varía la adición de una composición más en RM 689. En RM 697, Aqui comienzan unas coplas y romances (sin adscripción tipobibliográfica), la pieza se integra en unas coplas de disparates.

${ }^{23}$ Se trata de los pliegos de Alcaudete RM 9 (Burgos: Juan Bautista Varesio, no antes de 1593), RM 10 (Burgos: Felipe de Junta, $c$. 1564-1570), RM 11 (Burgos: Juan de Junta, $c$. 1535-1539), RM 12 (sin adscripción tipobibliográfica), RM 15 [+14 y 956] (Burgos: Juan de Junta, c. 1530-1535), así como de RM 750, Cancionero de galanes (Valencia, c. 1540) y RM 1034, Romance de los Condes de Carrión (Burgos: Junta, $c .1565-1570$ ). Como viene siendo habitual a lo largo de este trabajo, las dataciones y adscripciones tipobibliográficas manejadas proceden del Nuevo Diccionario bibliográfico de pliegos sueltos poéticos más su Suplemento, en el que se recogen las correspondientes a los pliegos sueltos burgaleses realizadas por Fernández Valladares, La imprenta en Burgos, ob. cit.; la excepción es la asignación correspondiente a RM 750, tomada de la base de datos Tipobibliografía valenciana de los siglos XV y XVI, dirigida por José Luis Canet y alojada en PARNASEO (Servidor web de Literatura Española de la Universidad de Valencia) [En línea]. Enlace: <https://parnaseo.uv.es/imprenta/publicacion/presentacion.html $>$ [Consulta: $28 / 02 / 2020]$. 
composiciones menores del poeta, que de la esparsa «Desde la hora que os vi» se hace eco, sin adscripción al autor, RM 159.5, Aqui comiençan muchas maneras de glosas, e canciones, e villancicos y coplas y motes hechos y glosados por Rodrigo Dávalos y otros autores (Barcelona: Amorós, 1540?) ${ }^{24}$.

Buen exponente de la popularidad que alcanzó la obra de Badajoz resulta, por otra parte, el proceso de anonimia conocido por sus Lamentaciones de amores, que en RM 502 (sin asignación tipobibliográfica) cierran, bajo la paternidad de nuestro poeta, un cuaderno con las Maldiciones de Salaya -sobre el que volveremos-, pero que en RM 922 (Burgos: Junta, c. 1535) encabezan el impreso bajo la rúbrica «Lamentaciones de amores hechas por un gentil hombre apasionado». Por fin, es sintomático tanto de la fama del autor como de la confusión de paternidades y atribuciones propia del medio la más que dudosa relación de Badajoz con el carolingio Romance de don Roldán $y$ de la traición de Galaron en el pliego colombino desconocido RM 48, un subgénero este, el del Romancero carolingio, característicamente ligado, por otra parte, a los inicios de la Literatura Popular Impresa ${ }^{25}$. De igual manera, altamente improbable es la conexión de su pluma con los versos «Salgan las palabras mías», adscritos a Garci Sánchez en RM 836 (Burgos: Junta, 1537), donde se glosan ${ }^{26}$.

En definitiva, cabe comentar que a los pliegos postincunables vinculados con Badajoz y encabezados por el largo poema amoroso se une la difusión del poeta en el ámbito a través de cuadernos algo más tardíos - pero mayoritariamente enclavados en la primera mitad del s. XVI- en los que se recoge alguna composición suya de forma aislada, generalmente piezas «menores» en posición de interior de impreso, con particular éxito del «romance» «Caminando por mis males», así como del villancico «De mi dicha no se espera», cuya transmisión, al igual que la de alguna canción, hemos visto que llega de manera anónima hasta la segunda mitad de la centuria. Comprobamos, pues, un proceso que habremos de corroborar con Encina y que adelantábamos en

\footnotetext{
${ }^{24}$ La adscripción tipobibliográfica de RM 159.5 ha sido tomada de Montserrat Lamarca, La impremta a Barcelona (1501-1600), Barcelona, Biblioteca de Catalunya, 2015, asiento n. ${ }^{\circ} 264$. En el Nuevo Diccionario se recoge, sin mayor especificación, la procedencia barcelonesa del pliego, así como su datación c. 1540 .

${ }^{25}$ Sobre el peso específico del Romancero carolingio en el arranque de la Literatura Popular Impresa, puede consultarse Puerto Moro, «El universo del pliego poético...», art. cit., pp. 266-268.

${ }^{26}$ Mucho más improcedente y cuestionable nos resulta referir dentro de esta nómina, si bien no dejamos de mencionarlo en nota al pie, la presencia en pliegos del villancico «El día del alegría», vinculado con Badajoz en el Cancionero de Londres, pero anónimamente recogido como deshecha del difundido romance «Dezime, vos, pensamiento» ya en la primera edición del Cancionero general, romance con el que se vincula como deshecha, siempre anónimamente, en los pliegos RM 658, 668, RM 870, RM 1038 y RM 1039, todos del primer tercio del s. XVI.
} 
páginas anteriores: la penetración más profunda en el ámbito y con mayor alcance temporal de los géneros cancioneriles menores. Al tiempo, son ostensibles en el proceso de asimilación en él de un Sánchez de Badajoz operaciones no solo de anonimia, sino falsas atribuciones y confusión de paternidades muy extendidas en los dominios de la Literatura Popular Impresa, sin olvidar el caso de contrafactum divino de RM 932.

Si Garci Sánchez de Badajoz es máximo exponente del pliego amatorio del periodo postincunable, no cabe la menor duda de que el lugar de poeta cortesano de mayor presencia en pliegos le corresponde a Juan del Encina. Transmisión anónima al margen, el amplísimo número de cuadernos poéticos en los que se hace presente el nombre del salmantino, casi una cuarentena -treinta y nueve exactamente, si no hay error de cómputo por nuestra parte-, en su mayor parte de la primera mitad del s. XVI - pero no solo-, junto con la existencia de enjundiosos trabajos clásicos sobre su transmisión en estas menudencias, así el llevado a cabo por Infantes en 1999, nos eximen de un análisis tan detallado como el desarrollado para Badajoz sobre la difusión enciniana en pliegos ${ }^{27}$. Sí queremos insistir, sin embargo, en el carácter crucial de la obra de Encina, más variada que la de Badajoz, a la hora de comprender la confluencia de tradiciones e interrelación entre «alta» y «baja» cultura sobre la que se gesta el despegue de la Literatura Popular Impresa. En esta línea, y refiriéndose exclusivamente a la producción poética -no teatral-del salmantino, ya Infantes ponía de relieve la selección temática sobre la que opera su acogida por el nuevo producto editorial: «Poesía religiosa y amorosa, disparates, romances, coplas con villancicos muy divulgados, villancicos de tópicos sentimentales y pastoriles, etc. $\rangle^{28}$, nómina sobre la que Beltran apostilla muy agudamente que «todas estas son variedades de la producción poética situadas en la parte más baja del registro cortés» (nuestras las cursivas), con insistencia por parte de este último crítico en la vinculación cortesana de los primeros tiempos del pliego poético ${ }^{29}$.

\footnotetext{
${ }^{27} C f r$. Víctor Infantes, «Hacia la poesía impresa. Los pliegos sueltos de Juan del Encina: entre el cancionero manuscrito y el libro poético», en Humanismo y literatura en tiempos de Juan del Encina, coord. por Javier Guijarro Ceballos, Salamanca, Universidad de Salamanca, 1999, pp. 83-99. Infantes contabilizó hasta treinta y cuatro pliegos poéticos en los que se recogen piezas del salmantino, número al que hemos de restar alguna noticia imaginaria corregida en el Suplemento al Nuevo Diccionario, y sumar, al tiempo, las nuevas entradas encinianas de ese Suplemento -donde figuran la totalidad de églogas con villancico-, lo que viene a computar esa totalidad de treinta y nueve pliegos quinientistas vinculados explícitamente con Juan del Encina.

${ }^{28}$ Ibidem, p. 93.

${ }^{29}$ Cfr. Vicenç Beltran, «Los primeros pliegos poéticos: alta cultura / cultura popular», en Revista de Literatura Medieval, 17 (2005), pp. 71-120, y, de este mismo autor, «Imprenta antigua, pliegos poéticos, cultura popular (-1516)», en La literatura popular impresa en España y en la América colonial. Formas \& temas, géneros, funciones, difusión, historia y teoría, dir. de Pedro M. Cátedra, ed. de Eva Belén Carro
} 
Ciñéndonos solo a la etapa postincunable, es reseñable que en ella se ubican más de una cuarta parte de los pliegos portadores de versos encinianos con autoría explícita, en total, once, pues entran en el cómputo no solo los tres cuadernos amatorios vistos anteriormente, sino otros cinco de carácter dramático que vienen a incorporarse al Suplemento al Nuevo Diccionario bibliográfico de pliegos sueltos poéticos (S. XVI) por la presencia en ellos del típico villancico de cierre teatral, más tres impresos romanceriles en los que un villancico amatorio de Encina se inserta en posición interior o directamente de remate.

Desde la restricción a la temática amorosa que aquí nos interesa, un rápido vistazo a esos tempranos cuadernos nos sitúa de inmediato ante el género del villancico como sello de identidad de la propagación del salmantino en el medio desde la etapa postincunable. En este sentido, hemos de comentar que si el asomo inicial en él de un Sánchez de Badajoz queda esencialmente asociado con el largo decir amoroso, el villancico enciniano prolifera en el ámbito desde la segunda década del s. XVI no solo gracias a la comentada miscelánea de RM 182 y RM 175.5, sino a través de las piezas suyas de esta índole incluidas en RM 1028, Romance del moro Calaynos (Sevilla: Cromberger, c. 1511-15) -con reedición en la imprenta sevillana c. 1520 (RM 1029)- y en RM 1040 (+184), Romance de un desafio que se hizo en Paris (Sevilla: Cromberger, c. 1511-15). En uno y otro impreso cumplen ya los villancicos de Encina una función de complemento o cierre de pliego que habrá de recorrer toda la centuria, aunque sea particularmente acusada su presencia en la primera mitad de siglo; ello, en acompañamiento tanto de romances como de piezas burlescas y dialógico-teatrales. Añadamos, además, que lo hacen con frecuencia de una manera anónima, lo que incide en el grado de intensa apropiación popular del autor.

En última instancia, la asimilación por la Literatura Popular Impresa de la obra de estos poetas inicialmente vinculados a Palacio y la atención al cómo se produce esa integración y a la selección textual sobre la que opera es insoslayable a la hora de comprender la confluencia entre tradición «mayor» $\mathrm{y}$ «menor» que cimienta sus inicios. Como no menos crucial resulta, en este sentido, la consideración y estudio de aquellos autores que, en cierta medida, toman el testigo de las grandes figuras cancioneriles a partir de los años veinte del s. XVI: los denominados autores galantes intermedios.

Carbajal et al., Salamanca, SEMYR, 2006, pp. 363-379. La cita está tomada de este segundo trabajo, p. 367. 


\section{La eclosión en pliegos de los autores galantes intermedios. Un estudio de caso: Alonso de Salaya}

Adelantábamos en páginas anteriores que la categoría de «autores galantes intermedios» ha sido recientemente aprehendida por la crítica en relación con toda una generación de poetas en pliegos del primer tercio del s. XVI, muchos de ellos con prolongación en el ámbito hasta la segunda mitad de siglo, caracterizados como:

Figuras al margen del servicio a los grandes nobles, no presentes en las compilaciones cancioneriles, pero muy cercanos a su estética en la composición amorosa y que se nos muestran, al tiempo -y sobre todo-, como adiestrados glosadores de romances, así como, en ciertos casos, compositores de piezas burlescas. Como fuere, moviéndose básicamente en los límites del entretenimiento literario, frente a la solemnidad de la composición religiosa o de tipo político $^{30}$.

Erigidos en auténticos puentes entre la «alta» y «baja» cultura, el corpus básico de autores que entran dentro de esta categoría ha sido establecido por Puerto Moro: Gonzalo de Montalbán, Francisco de Lora, Alonso de Alcaudete, Alonso de Salaya, Melchor de Llanes, Pedro Tirante, Fernando de Villareal, López Ortiz de Zúñiga o Francisco de Marquina, además del prolífico, y descollante dentro del grupo por varios motivos, Rodrigo de Reinosa ${ }^{31}$. Son todos ellos nombres presentes en los registros colombinos o vinculados con cuadernos que han podido datarse en los años veinte y treinta del s. XVI. Esta circunstancia, más su ausencia en la etapa postinincunable -con la excepción del singular Rodrigo de Reinosa-, nos lleva a afirmar sin tribulaciones que eclosionan en el medio esencialmente a partir de la tercera década del Quinientos, tomando hasta cierto punto el relevo de los grandes poetas cancioneriles -si bien llegan a convivir-y abasteciendo ahora un nuevo mercado, el del pliego poético, para el que se está fraguando toda una tradición propia de nombres y textos. Es la constatación de esa irrupción a partir de los años veinte fundamentalmente la que, por otra parte, permite apoyar desde laderas literarias las más que serias dudas que para una autoridad en tipobibliografía como Fernández Valladares plantea la adscripción de c. 1503 de RM 375, Glosa de Esperança mía, de Gonzalo de Montalbán, tempranísima datación

\footnotetext{
${ }^{30} C f r$. Laura Puerto Moro, «Sobre "autores galantes intermedios”...», art. cit., la cita en las pp. 261262.

${ }^{31}$ Ibidem, p. 262.
} 
de la que se hacía eco el mencionado estudio de Puerto Moro a partir del catálogo de postincunables de Martín $\mathrm{Abad}^{32}$.

Al lado de la recreación de la estética cancioneril en sus piezas amorosas, es práctica especialmente extendida entre estos autores, señalábamos, la glosa de romances ${ }^{33}$; un ejercicio bien conocido en el universo del pliego poético desde la etapa postincunable, en la que hasta seis de la treintena de cuadernos romanceriles de carácter literario conocidos responden a la técnica de la glosa o aditamento cortesano, siendo, de hecho, esta la tipología de pliegos de romances más abundante en el periodo tras los carolingios ${ }^{34}$. Sobra recordar, en relación con todo ello, que la glosa de romances fue en sus primeras manifestaciones una conocida práctica palaciega, particularmente en auge durante la época de los Reyes Católicos, además de forma por excelencia por la que se produjo la entrada en nuestra historia literaria no solo del Romancero tradicional, sino de toda la Lírica popular. En ese sentido, puede decirse que, en sus inicios, el ejercicio de la glosa poética es tan consustancial a la convergencia entre tradición «mayor»y «menor» como clave en el encuentro resulta la proliferación en pliegos de esos autores galantes intermedios que hacen de ella una de sus señas de identidad.

\footnotetext{
${ }^{32}$ Tal y como señala Fernández Valladares en Fernández Valladares, Puerto Moro y Mahiques Climent, $o b$. cit., el pliego, significativamente, no fue recogido por Norton en su magno catálogo de postincunables (A descriptive catalogue of printing in Spain and Portugal 1501-1520, Cambridge, Cambridge University Press, 1978), pese a que es impreso preservado en la BNE al que el tipobibliógrafo tuvo acceso. Por su parte, Griffin lo asigna con la mayor cautela a «Seville?, Cromberger press?, 1503 or later?», ya en su primer repertorio (The Crombergers of Seville. The History of a Printing and Merchant Dinasty, Oxford, Clarendon Press, 1988, n. ${ }^{\circ}$ 8), asignación mantenida en la versión española (Los Cromberger. La historia de una imprenta en Sevilla y Méjico, Madrid, Ed. de Cultura Hispánica, n. ${ }^{\circ}$ 8). La simplificación a «Sevilla, Jacobo Cromberger, 1503 o posteriormente», se debe a Martín Abad, ob. cit., n. ${ }^{\circ}$ 1077. De este catálogo toma la adscripción tipobibliográfica Puerto Moro, «Sobre "autores galantes intermedios"...», art. cit., p. 259. En correspondencia mantenida con la Profa. Fernández Valladares, nos hace notar que, de acuerdo con las apreciaciones de Griffin, la tipografía del pliego dejó de usarse en la imprenta de los Cromberger antes de 1516, pero volvió a reponerse posteriormente, en los años finales de la década de los treinta, por lo que resulta sumamente incierta su datación temprana, y se hace necesaria una reconsideración tipobibliográfica, máxime teniendo en cuenta que es pliego inventariado en el Abecedarium colombino con el n. $^{\circ} 15128$, número por el que se puede deducir que probablemente fue adquirido en Valladolid hacia mediados de septiembre de 1536 con un conjunto de obras que abarcan desde el registro 15110 al 15137, algunas de ellas conservadas en la propia Biblioteca Colombina y con anotación de compra, llevando este, concretamente, la fecha explícita de 1536. A partir de todo ello, deberíamos considerar el llevar la cronología de RM 373 a finales de los años treinta.

${ }^{33} \mathrm{La}$ excepción la constituye, una vez más, la producción de Rodrigo de Reinosa. Cfr. Laura Puerto Moro, Obra conocida de Rodrigo de Reinosa, San Millán de la Cogolla, Cilengua, 2010.

${ }^{34} \mathrm{Ha}$ de hacerse notar que en los pliegos del periodo postincunable esas glosas de romances corresponden a plumas cortesanas o se presentan directamente como anónimas, nunca, en cualquier caso, bajo la autoría de alguno de los autores galantes intermedios anteriormente inventariados, dentro de la que constituye una lógica correspondencia con la cronología marcada para tales poetas.
} 
Buen glosador de romances, además de delicado autor de piezas amatorias de ascendencia cancioneril, fue Alonso de Salaya, figura tan carente de un estudio que permita contextualizar adecuadamente sus claves compositivas como perfecta ejemplificadora de la producción propia de la categoría autorial que ahora nos interesa, por lo que ocupará nuestra atención en las próximas páginas ${ }^{35}$. Sobre él afirmó José Manuel Blecua:

Salaya es, sin duda, uno de los mejores poetas de pliegos sueltos, muy ágil en la versificación y no exento de gracia poética. Enraizado en la tradición cancioneril, sus romances aconsonantados tienen indudable encanto, lo mismo que sus canciones y villancicos ${ }^{36}$.

De Alonso de Salaya o Selaya, del que nada sabemos sobre su vida -hecho común para estos autores, salvo alguna iluminadora excepción ${ }^{37}$, si bien se ha juzgado montañés por el apellido ${ }^{38}$, conocemos, además del notable legado en menudencias, una pieza teatral, la llamada Farsa de Salaya, lo que lo acerca a la producción de otros poetas clasificados como «galantes intermedios» en la que también se incluyen composiciones dramáticas, caso de un Lope Ortiz de Zúñiga, con su perdida Farsa en coplas de Calisto y Melibea $^{39}$. En cuanto a la Farsa de Alonso de Salaya, se inscribe plenamente en la estela naharresca, en ocasiones con préstamos literales del extremeño, filiación que bien se aviene con la ubicación de Salaya en el primer tercio

${ }^{35}$ José María Cossío lo incluyó en sus Rutas literarias de la montaña, Santander, Diputación Provincial, 1960, pp. 441-447. Mercedes Fernández Valladares y Víctor Infantes dan una breve «noticia» sobre el autor y editan la parte poética de su obra en Pliegos cántabros del siglo XVI (poesía). Juan de Trasmiera, Alonso de Salaya, Ruyz de Santillana, Santander, Ed. Cuévano, 1985, si bien solo parcialmente, ya que estos investigadores no tuvieron acceso en aquel momento a un pliego de Salaya fundamental para aprehender su producción, el RM 509. El impreso en cuestión, que perteneció al Duque de T'Serclaes, se halla en la actualidad en paradero desconocido; no obstante, existe reproducción fotográfica en la Fundación Menéndez Pidal, a la que se puede acceder a través de su Archivo Digital del Romancero (ID: C002-001-0003).

${ }^{36}$ Pliegos poéticos del siglo XVI de la Biblioteca de Cataluña. Edición en facsímile precedida de una introducción por José Manuel Blecua, Madrid, Joyas Bibliográficas, 1976, p. 24.

${ }^{37}$ Constituye esta excepción el caso de Gonzalo de Montalbán, de quien podemos deducir, a partir de la rúbrica de RM 373, que compuso la Glosa de Esperança mía recogida en tal pliego siendo soldado al servicio del capitán Pedro López de Orozco, apodado «el Zagal», según se detalla en Puerto Moro, «Sobre “autores galantes intermedios”...», art. cit., p. 261.

${ }^{38}$ Nos remitimos a su inclusión entre poetas montañeses por Cossío, ob. cit., y por Infantes y Fernández Valladares, ob. cit.

${ }^{39}$ Es obra bien conocida por la crítica teatral que recientemente recoge Joseph E. Snow en su Apéndice de «Obras españolas que fluyen de Celestina, siglos XVI-XVII», incluido en «Celestinas en el imaginario del siglo XVI», en Letras, 73 (2016), pp. 169-188, en particular, pp. 179-183. 
del s. XVI o poco después a la que comprobaremos que nos llevan también los pliegos que transmiten sus versos ${ }^{40}$.

Al margen de su difusión anónima en el medio, diez son los cuadernos quinientistas que recogen la obra de Alonso de Salaya bajo explícita paternidad del poeta, dos de ellos colombinos desconocidos, de manera que no pueden ser datados más allá de 1539 (RM 505 y RM 506.5). Por lo que a los otros ocho se refiere, todos carentes de pie de imprenta, es reseñable que de los tres para los que contamos con adscripción tipobibliográfica, los tres burgaleses procedentes del taller de los Junta, dos son fechados c. 1530-35 (RM 506 y RM 509), mientras que el tercero nos transporta a la segunda mitad del Quinientos: c. 1560-1570 (RM 507). Solo a partir de estos datos se hace necesario insistir en que nos encontramos ante una figura cuya producción estaría viviendo en pliegos desde el primer tercio del s. XVI, alcanzando las sucesivas ediciones de sus glosas de romances la segunda mitad de la centuria, circunstancias que casan perfectamente con lo anteriormente expuesto sobre la cronología de estos autores.

Antes de adentrarnos en la glosa de romances y, sobre todo, en las composiciones amatorio-cancioneriles del poeta, hemos de hacer una breve cala en los que fueron los versos que le habrían de convertir en proverbial: las Maldiciones de Salaya ${ }^{41}$, a las que no hacen referencia ya el Diccionario de Sánchez de la Ballesta (1587) y que habrán de ser aludidas también -y entre otras obras de contenidos paremiológicos- en el Vocabulario de Correas $(1627)^{42}$. La pieza en cuestión se sitúa en la convergencia entre el motivo del vituperio del sirviente como detonante temático y el perqué-disparate como modulación formal de «una cadena gigantesca de dísticos-maldiciones [...] cómicamente desproporcionada contra el trivial robo de una capa», en

\footnotetext{
${ }^{40}$ Sobre la Farsa y sus fuentes, véase el clásico estudio de Joseph E. Gillet, «Farsa hecha por Alonso de Salaya», en Modern Language Association, 52:1 (1937), pp. 16-67. Ha de tenerse en cuenta, no obstante, que Gillet, desconociendo la cronología de los pliegos de Salaya, situó la obra $c$. 1556 por interpretación errónea de una referencia interna. Por su parte, Fernández Valladares, La imprenta en Burgos, ob. cit., p. 1317, al examinar el único ejemplar conocido de la Farsa, afirma que «tanto las dos tipografías del texto, como algunos de los tacos xilográficos de figurillas y los adornitos tipográficos que forman la orla, aparecen en varias ediciones impresas por Pedro de Casto en Medina del Campo, en torno a los años 1541-1543». Ello no quiere decir, obviamente, que la creación de la pieza teatral no sea anterior.

${ }^{41} \mathrm{La}$ crítica viene dando por hecho que los versos son de Alonso de Salaya, si bien cabe comentar, aunque sea a pie de página, que en ninguno de los pliegos que transmiten las Maldiciones se incluye el nombre propio del autor, tal vez por su temprana popularidad.

${ }^{42}$ Es información que recoge ya Gillet, art. cit., pp. 21 y 22, quien, además, añade que dos de los versos de las Maldiciones, «De los osos seas comido / como Favila el nombrado», son referidos por Sancho Panza en El Quijote (II. 34), sugiriendo, no obstante, que la cita pudo ser tomada no de las Maldiciones, sino de algún romance perdido sobre el rey Favila de Asturias.
} 
palabras de Blanca Periñán ${ }^{43}$. No falta en la composición la carga de cierta erudición que implica la introducción de «historias castellanas», «historias romanas», «historias grecianas» y «fábulas infernales» como referentes de las maldiciones vertidas en unos versos que se construyen sobre la bien conocida práctica popular y literaria de la imprecación.

Las Maldiciones se transmiten hasta en cuatro pliegos quinientistas, ninguno de ellos datado: en tres encabezan el cuaderno y son completadas, respectivamente, por las Lamentaciones de Garci Sánchez de Badajoz (RM 502), ya mencionadas en este trabajo al estudiar la obra de Badajoz, por un Aparato de guerra de Antón de Montoro recogido en la sección de burlas del Cancionero general (RM 503) y por dos romances bien conocidos del ciclo castellano (RM 504); cuadernos estos a los que hay que sumar la función de remate de la pieza en RM 212, Coplas hechas por Diego García. Este contacto de las Maldiciones con composiciones de la compilación de Del Castillo ya en RM 502 y en RM 503 parecería preludiar, de alguna manera, la que será la posterior inserción de las Maldiciones en la Segunda parte del Cancionero general agora nueuamente compilado de lo mas gracioso y discreto de muchos afamados trovadores, impresa por Esteban de Nájera en 1552 en un tamaño en dozavo que denuncia, desde el formato mismo, el grado de popularización a esas alturas del s. XVI de una compilación en la que, para mayor elocuencia de datos, se introducen ahora varias composiciones más que sabemos a ciencia cierta que estaban circulando en pliegos ${ }^{44}$. En última instancia, todo ello no haría sino incidir en las complejas interrelaciones entre pliegos y Cancionero que venimos estudiando a lo largo del presente trabajo.

Aún más difundida que sus Maldiciones, si es que atendemos a los testimonios, fue la glosa de Salaya al Romance de la reina troyana, que recogen bajo su autoría hasta cinco impresos, dos de ellos los referidos pliegos colombinos desconocidos RM 505 y RM 506.5, a los que se suman la transmisión

\footnotetext{
${ }^{43}$ Blanca Periñán, Poeta Ludens. Disparate, perqué y chiste en los siglos XVI y XVII, Pisa, Giardini, 1979 , p. 33. Sobre la presencia en pliegos poéticos del tradicional motivo del vituperio del sirviente y sus conexiones con el primer teatro renacentista, puede consultarse Laura Puerto Moro, «Expresiones dramáticas en el s. XVI: pliegos poéticos dialogados y teatralidad (con un apunte sobre sus ilustraciones)», en Hacia un primer teatro clásico: El teatro del Renacimiento en su laberinto, ed. de Julio Vélez, MadridFrankfurt am M., Iberoamericana-Vervuert, 2019, pp. 17-34, en particular, pp. 23-24.

${ }^{44}$ Cfr. Antonio Rodríguez-Moñino, «Introducción» al Cancionero general recopilado por Hernando del Castillo (Valencia, 1511). Sale nuevamente a la luz en facsímile por acuerdo de la Real Academia Española, con una introducción bibliográfica, índices y apéndices por Antonio Rodríguez-Moñino, Madrid, Real Academia Española, 1958, pp. 34-38. Véase también el apartado que el bibliógrafo extremeño dedica a la remodelación del Cancionero general de Nájera en su imprescindible Poesía y cancioneros (siglo XVI). Discurso leído ante la Real Academia Española el día 20 de octubre de 1968 en su recepción pública, Madrid, Artes Gráficas Soler, 1968, reeditado en Antonio Rodríguez-Moñino, Estudios y ensayos de literatura hispánica de los Siglos de Oro, ed. de Víctor Infantes, Cáceres, Genueve Ed., 2012, pp. 83-198.
} 
en los pliegos gemelos RM 506 (c. 1530-1535) y RM 508 (sin adscripción tipobibliográfica), más en RM 507 (c. 1560-1570). De la popularización que alcanzó la glosa da idea, por otra parte, su circulación anónima en RM 917.5 (1540?), incluyéndose aquí los versos en una miscelánea de glosas de romances tradicionales y trovadorescos ${ }^{45}$, y en RM 918 (1573-1575?), cuaderno emparentado con el anterior que añade unas coplas de remate ${ }^{46}$.

No nos detendremos específicamente en la glosa del romance troyano, pero sí nos interesa resaltar, al objeto de la confluencia de tradiciones que se halla en el ADN de la producción de los autores galantes intermedios que, si seguimos la interpretación de Gamba Corradine en un recentísimo trabajo sobre los romances de materia troyana, estos «comenzaron a escribirse a principios del siglo XVI en contextos cultos, como una suerte de promoción de algunos textos en prosa», recordando, en relación con el Romance de Amadís atribuido a Salaya que acompaña a nuestra glosa en todos los pliegos vinculados con su nombre -a excepción de RM 506.5- que «esta fusión de contenidos en el pliego evidencia [...] que la materia troyana, muy posiblemente, fue asumida por impresores y lectores en el marco de los nuevos géneros impresos caballerescos del siglo XVI $\rangle^{47}$. Podemos dudar sobre si el adjetivo de «cultos»-«contextos cultos»- utilizado por Gamba Corradine es totalmente preciso a la hora de indagar en el proceso de gestación de esos romances troyanos, pero de lo que no nos cabe la menor duda es de su ubicación en la encrucijada entre tradición «mayor» $\mathrm{y}$ «menor» que aquí venimos estudiando, la misma en la que se sitúa el romance amadisiano y su adscripción a la bien conocida práctica en el ámbito de la Literatura Popular Impresa de abreviación y versificación en pliegos de novelas y bestsellers del momento. Y, al hilo, hemos de comentar que, de acuerdo con García de Enterría en un clásico estudio sobre los romances de Amadís, cabría hablar de una «"escuela" de romancistas que a principios del s. XVI versificaban o romanceaban obras cultas», en un intento por «popularizar los temas» y «provocar una reacción a favor de estos libros que empujara a la lectura de ellos» ${ }^{48}$.

${ }^{45}$ «La glosa de romançe que dize rosa fresca, rosa fresca: y la glosa de la reyna Troyana: e la glosa de Mora Morayma: e la glosa de la mía gran pena forte». De acuerdo con Lamarca, ob. cit., n. ${ }^{\circ} 268$, es pliego procedente de la imprenta barcelonesa de Carles Amorós, indicando como datación «1540?».

${ }^{46}$ «La glosa del romanze que dize rosa Fresca, rosa fresca. Y la glosa de la Reyna Troyana: y la glosa de Mora morayma: \& la glosa de la mia gran pena forte. Y unas coplas a una serrana». Su adscripción tipobibliográfica es «Barcelona. Claudi Bornat. 1573-1575?», siguiendo a Lamarca, ob. cit., n. ${ }^{\circ} 596$.

${ }^{47}$ Véase Jimena Gamba Corradine, "“Triste estaba y muy penosa": sobre la formación del romancero erudito y sobre los ciclos de romances», en Atalaya, 18 (2018), párrafos 28 y 17. [En línea]. Enlace: $<$ https:// journals.openedition.org/atalaya/3253> [Consulta: 28/02/2020]. DOI: https://doi.org/10.4000/atalaya.3253.

${ }^{48}$ Nos remitimos a María Cruz García de Enterría, «Libros de caballerías y romancero», en Journal of Hispanic Philology, 10 (1986), pp. 103-115. La cita en la p. 107. 
En RM 506 la Glosa del romance de la reina troyana y el Romance de Amadís son completados, además de por un villancico del mismo Salaya sobre el que nos detendremos inmediatamente, por dos romances de Gaiferos no pertenecientes a nuestro vate y de vida propia en el medio, ajenos, por tanto, al objeto de investigación que nos atañe. Más nos interesan los pliegos gemelos RM 507 y RM 508, donde la Glosa del romance de la reina troyana y el Romance de Amadis se presentan acompañados por un conjunto de composiciones amorosas del poeta, en la línea de combinación entre romances literarios y versos de tal índole habitual en estos autores. Concretamente, hasta ocho son las piezas amatorias de Alonso de Salaya incluidas en RM 507 y RM 508, lo que viene a constituir todo un conjunto poético claramente «enraizado en la tradición cancioneril»-en las reproducidas palabras de José Manuel Blecua-.

La primera de esas ocho piezas, el villancico que lleva por estribillo «Quién será que sea covarde / en presencia del amor / si él muestra su favor», es, en realidad, deshecha del Romance de Amadís que le precede en la totalidad de pliegos que lo transmiten, en conexión con la narración en él del encuentro amoroso entre Amadís y Oriana. En cuanto a la composición siguiente, Romance de Salaya a una señora, queda inscrito plenamente en la línea cancioneril de presentación y explicación de la fenomenología amorosa a través de personificaciones alegóricas ${ }^{49}$. De esta manera, se nos expone cómo el poeta, «cercado de gran pesar», es convidado por la Tristura a yantar a la casa real de la Pena, cuyo portero es el Desear «que a plazeres no da puerta / mas abre las del pesar», con descripción de una comida en la que es el Cuidado «mastresala / que viene con el manjar» y la bebida el vino «manado de mi llorar», finalizando la alegoría con la entrada en escena de «un niño ciego / con muy grande auctoridad» que prende al protagonista, para, en los versos finales, presentársenos la tópica solicitud de compasión de la amada como única forma de liberación de la pena de amor. A modo de deshecha, sigue al romance el villancico que principia «Gloria me será una muerte / y no mil muertes morir / con tan penoso vivir», recreando el remanido motivo cancioneril de la muerte de amor.

Los dos versos que abren el siguiente romance de Salaya, bajo la escueta presentación de Otro romance, «Dormiendo está el pensamiento / quel pesar lo adormecía», son prácticamente idénticos a los que inician un romance de Núñez presente ya en el Cancionero general de 1511 y que tuvo gran

\footnotetext{
${ }^{49}$ Puede verse, por ejemplo, todo el apartado dedicado a personajes alegóricos y personificados en Estela Pérez Bosch, Los valencianos del Cancionero General: estudio de sus poesías, Valencia, Universitat de Valencia, 2009, pp. 239-245.
} 
difusión: «Durmiendo estaba el cuidado / quel pesar lo adormescía», circunstancia que alguna vez ha llevado a la crítica a una errónea identificación entre ambas piezas, y que, antes bien, nos estaría hablando a las claras del cerrado universo cancioneril en que nos movemos y de su cristalización en reconocibles estilemas -versos completos incluidos- de los que no dudan en apropiarse estos autores galantes intermedios ${ }^{50}$. En la estela del romance anterior, Salaya nos sitúa de nuevo ante una visión alegórica en la que, dentro del consabido marco del sueño poético, el Pensamiento contempla al Cuidado lamentándose del fuerte combate que mantiene con el Amor, teniendo aquel como baluartes Fe y Esperanza, para, a continuación, ser el poeta mismo quien se encuentra con el omnipotente Amor, poniéndose a su servicio a cambio de un sueldo de «cinco mil congoxas, / penas y malencononía / dolor y muchos trabajos, / pasiones y gran porfía», con referencia explícita, en los versos finales, a la tópica muerte de amor: «En servicio del amor / muerta está la vida mía». Es rematado el romance por una «Defecha» simple y breve: «Lloran mis ojos / y mi coraçón / con mucha razón».

También plenamente inserta en la tradición cancioneril se encuentra la composición siguiente, Coplas de Salaya a una señora que traya en el trençado dos colores de verde y pardillo, en este caso, dentro de la bien conocida poesía de circunstancias, con convergencia en las coplas de dos motivos sumamente recurrentes en esa poesía: la referencia a una prenda y el juego con la simbología de los colores ${ }^{51}$. Se convierten de esta manera el verde y pardillo del trenzado de la amada en expresión, respectivamente, de la esperanza y congoja del poeta.

Por fin, nos encontramos con dos canciones y un villancico en la última página del cuaderno, acorde a la posición de remate de pliego que ocupan con frecuencia este tipo de piezas menores. La primera canción se ajusta a la que había sido la evolución formal del género a finales del siglo Xv, caracterizada

\footnotetext{
${ }^{50}$ No fue ajeno a esta confusión de composiciones Gillet, ob. cit., p. 21, quien consideró que el romance de Salaya habría sido incluido en la Primera Parte de la Silva de varios romances impresa por Esteban de Nájera en 1550, cuando es el de Núñez el allí presente. De la misma manera, se localiza el romance de Núñez en la Silva de varios romances de Barcelona, 1550, y en la Primera parte de la Silva de varios romances de Barcelona, 1552, al margen de su presencia en las sucesivas ediciones quinientistas del Cancionero general y en varios pliegos sueltos (RM 935.5, RM 936, RM 1038 y RM 1039). Para la transmisión de la composición en las Silvas y en el Cancionero general, $c f r$. Antonio Rodríguez-Moñino, Manual bibliográfico de cancioneros y romanceros I. Impresos durante el siglo XVI, coord. Arthur L.-F. Askins, Madrid, Castalia, 1973, 2 vols.

${ }^{51}$ Una buena síntesis del lugar de la poesía de circunstancias en el Cancionero y sus particulares rasgos definitorios es la presentada por Ana M. Rodado Ruiz en Tristura conmigo va. Fundamentos del Amor Cortés, Cuenca, Universidad de Castilla-La Mancha, 2000, pp. 153-162. Asimismo, se puede consultar Pérez Bosch, ob. cit., pp. 310-317.
} 
por la reducción a una sola estrofa y por la tendencia a la concisión ${ }^{52}$; basta leer su estribillo para identificar el archiconocido léxico, tópica y retórica cancioneriles que reproduce: «Mis passiones y tormentos / son a mí gloria cumplida, / pues que della soys servida». Más alejada de los parámetros prototípicos de la canción finisecular se encuentra la siguiente pieza, Otra canción a una señora que no cumplió lo que avía prometido, con desarrollo a través de dos vueltas de un estribillo que reza: «¿Quién podrá vivir mirando / vuestra tan falsada fe? / Maldita la hora quando / con mis ojos os miré». Por lo que se refiere al villancico final, en torno al tópico del enamoramiento a través de la vista - «Contraria me fue ventura / quando os vi, / porque en veros me perdí»)-, hay que comentar que debió de tener cierta difusión, pues se recoge -con una pequeña variante- no solo en otro pliego de Salaya, el mencionado RM 503 en el que una pieza de Montoro completa las Maldiciones, sino en RM 885.5, Glosa del romance que dize Por la matança va el viejo (Barcelona: Amorós, 1540?), de forma anónima en este último caso y, una vez más, rematando glosas de romances ${ }^{53}$.

Estructura en gran medida similar a la de RM 507 y RM 508 es la que detectamos en RM 509, Romance de don Tristán nuevamente glosado por Alonso de Salaya con otras obras suyas, impreso en Burgos, c. 1530-1535 por Juan de Junta. De nuevo, a la inicial glosa de un romance, caballeresco en este caso, le sigue un romance amoroso de anclaje alegórico rematado por un «villancico» en función de deshecha. Se incluyen en el impreso tres composiciones más que basculan entre los conocidos polos de exaltación y denostación del amor, todas ellas atribuidas a Salaya en el encabezamiento del pliego, a pesar de que cuando menos la última pertenece a Juan del Encina.

Fieles al objeto de este estudio, una vez más, no profundizaremos en la glosa de romance que abre el cuaderno, si bien no hay que olvidar que un Romance de don Tristán era ya escuchado en la corte de los Reyes Católicos, según testimonia la alusión a él en el Juego trovado o Juego de naipes dedicado a la reina Isabel por Jerónimo del Pinar c. 1497 (recogido en el Cancionero general 1511$)^{54}$, por una parte, $\mathrm{y}$, por otra, que resulta probable la conexión

${ }^{52} C f r$., por ejemplo, entre otros trabajos de este estudioso, Vicenç Beltran, Edad Media: lírica y cancioneros, Madrid, Visor, 2009, p. 59.

${ }^{53}$ La adscripción tipobibliográfica, no incluida en el Nuevo Diccionario ni en su Suplemento, se la debemos a Lamarca, ob. cit., n. ${ }^{\circ} 267$.

${ }^{54}$ Se hace eco de ello María Luzdivina Cuesta Torre, «Tristán en la poesía medieval peninsular», en Revista de Literatura Medieval, 9 (1997), pp. 133-134, recogiendo además, los versos correspondientes de la composición de Pinar: «Un fresno, dama, os presento, / con una grúa crescida, / y, entre tanto, el pensamiento / piensa en que serés seruida; / y el romance que aquí os dan, / es aquel c'aueys oydo, / mucho triste y dolorido: / Mal se quexa don Tristán; / y el refrán dicho por nombre: Que a las ueces lleua el 
del romance con el Libro del esforçado caballero don Tristán de Leonís y de sus grandes fechos en armas -del que conservamos una primera edición conocida de 1501-, a la manera en que se vinculan los romances amadisianos con el correspondiente relato caballeresco, dentro del visto cruce de tradiciones en que se sitúan tales composiciones ${ }^{55}$. De hecho, no es descartable que la glosa de Salaya se relacione con alguna de las sucesivas ediciones que conoció la mencionada novela de Tristán durante el primer tercio del s. $\mathrm{XVI}^{56}$. Por lo demás, y centrándonos en la fortuna de la glosa, hubo de gozar de una cierta popularidad, pues la hallamos de forma anónima en un pliego de los años cuarenta impreso por Amorós en Barcelona (RM 883.5), así como, también anónimamente, en dos pliegos burgaleses de Felipe de Junta de los años sesenta (RM 882 y RM 883) $)^{57}$.

La pieza que le sucede es, adelantábamos, un romance de carácter alegórico-amoroso en la línea de los anteriormente analizados, tipo de composición esta que parece que fue tan cara a Salaya como la glosa de romances y en la que muestra cierta destreza y maestría. Es más, incluso comparte con el primero de los romances estudiados el verso inicial, «En mis pasiones pensando», dentro de los comentados parámetros de recurrencia cancioneril no ya de unos determinados motivos, léxico y retórica, sino de versos enteros ${ }^{58}$. El autor, partiendo una vez más del marco narrativo del sueño, nos sitúa ahora ante el conocido subgénero cancioneril del infierno de amor-«halleme cativo, preso / de mi voluntad forçado, / en el infierno del amor / súbitamente

ombre...». Téngase en cuenta, no obstante, que la versión que glosa Salaya y la única que se recoge en pliegos quinientistas comienza «Ferido está don Tristán...».

${ }^{55}$ La posibilidad de vinculación entre el romance glosado por Salaya y el Libro del esforçado caballero don Tristán de Leonís queda señalada por Di Stefano en su edición de aquel, véase Giuseppe Di Stefano, Romancero, Madrid, Castalia, 2010, p. 175.

${ }^{56}$ Sobre la posible funcionalidad del tipo de romance caballeresco glosado como promoción comercial de la novela o relato correspondiente, se hace necesario referirse, más allá de las palabras anteriormente reproducidas de García de Enterría en relación con los romances amadisianos, a un clásico artículo de Nieves Baranda en el que estudia el Romance nuevamente trovado del infante Turián y de la infanta Floreta en conexión con la salida editorial de la Historia del rey Canamor. Cfr. Nieves Baranda, «Historia caballeresca y trama romanceril: La Historia del rey Canamor y el Romance del Infante Turián», en Studi Ispanici, 10 (1985), pp. 9-31, en particular, pp. 21-25. Por lo que se refiere a las sucesivas ediciones quinientistas de la novela de Tristán, puede consultarse María Luzdivina Cuesta Torre, «La transmisión textual de Don Tristán de Leonís», en Revista de Literatura Medieval, 5 (1993), pp. 63-93.

${ }^{57}$ La asignación tipobibliográfica de los pliegos burgaleses - «Burgos, Felipe de Junta, c. 1560-1565» para RM 882 y «Burgos, Felipe de Junta, $c$. 1564?» para RM 883- corresponde a Fernández Valladares y se encuentra recogida en el Suplemento al Nuevo Diccionario. Por lo que se refiere al pliego barcelonés, su adscripción tipobibliográfica-«Barcelona. Carles Amorós. 1540?»- se debe a Lamarca, ob. cit., n. ${ }^{\circ} 266$.

${ }^{58}$ No existe, no obstante, una identidad textual entre el romance de uno y otro pliego, error en el que comprensiblemente cayeron Infantes y Fernández Valladares, ob. cit., p. 11, a partir de ese primer verso al no haber podido leer, en su momento, el pliego que ahora estamos analizando, según quedó expuesto en nota supra. 
llevado»-, subgénero del que, dentro de nuestro corpus, hallábamos ya un excelente ejemplo bajo el formato del largo decir en Sánchez de Badajoz. En ese infierno de amor, el poeta ve desfilar tras el carro dorado del «niño ciego» tres mil presos «qu'él mismo avíe cautivado», encabezados por el poeta enamorado por antonomasia, Macías, al que siguen toda una sarta de conocidos amantes de la Antigüedad Clásica y de la literatura medieval hasta llegar a los mismos «Calisto y Melibea / y su caso desastrado», sin que falten en la nómina de subyugados por el dios Amor, y en refuerzo de su omnipotencia, animales de todas las especies - «Tigres, Ossos, Elefantes»- entre los que tienen lugar propio aves de clara simbología amorosa -«Papagays, Ruyseñores»-. Terminan los versos con la habitual solicitud a la amada para que remedie el sufrimiento del poeta, dentro del también tópico augurio de que «entre todos amadores / por mayor seré contado». Bajo la rúbrica de «villancico», son deshecha del romance los siguientes versos: «No quiero sino serviros, / siempre yo vuestro seré, / aunque quede con sospiros, / dama, con vuestra mercé».

A continuación del romance y su deshecha figura un «Derreniego a una dama» que Blanca Periñán refiere como «perqué-maldición íntimamente ligado al género de los fieros o enfados» «calcando el tópico de los improperia» ${ }^{59}$. En él, tras unos breves versos introductorios - «Son mis penas tan crecidas / en la mar donde navego, / señora, / que derreniego / dellas y su condición / y con desesperación / derreniego y no de dios [...]»-, comienza la larga tirada de «derreniegos», en los que se repasan múltiples aspectos de la sociedad de la época. Nada hay en este Derreniego que nos incite a dudar sobre la autoría de Alonso de Salaya, pese a su transmisión anónima en un pliego de la segunda mitad del s. XVI (RM 1081), sin embargo, sí nos provoca serias dudas la adscripción a nuestro autor de la composición siguiente, «Coplas en loor de una dama», sustentadas sobre el motivo de la imposibilidad de expresión de la belleza de la amada, cuya factura es claramente inferior a la que nos tienen acostumbrados los versos de probada paternidad de Salaya. Por otra parte, nuestra duda se halla más que fundada si tenemos en cuenta que la última pieza del cuaderno es a todas luces de Encina - «Juan del Encina despidiendo el amor»-, lo que no ha impedido que el encabezamiento del pliego atribuya todas las obras que lo integran a Alonso de Salaya.

En síntesis, podemos afirmar que en Salaya el romance de componente alegórico-amoroso, sistemáticamente en posición de interior de impreso, viene a tomar el relevo, de alguna manera, de los amplios y alambicados poemas -frecuentemente decires- que abrían los pliegos amatorios más

${ }^{59}$ Blanca Periñán, ob. cit., p. 90. 
idiosincráticos de la etapa postincunable. Acompañan siempre a esos romances otras piezas menores, fundamentalmente villancicos en función de deshecha o canciones diversas -al margen de composiciones amorosas de otro tipo que puedan completar el pliego-; todo ello en significativa combinación con el género de la glosa de romances como prototípica apertura de cuaderno y reclamo editorial.

$$
* * *
$$

En la páginas precedentes nos hemos adentrado en la manera en que se produce el proceso de apropiación del Cancionero por el universo de la Literatura Popular Impresa a través de la que es su temática por antonomasia, la cortesano-amorosa, así como en el peso específico que posee este proceso en la andadura inicial del nuevo producto editorial del pliego poético; un análisis que nos ha llevado desde los nombres cancioneriles de primera línea que monopolizan los cuadernos postincunables hasta la gran eclosión en el ámbito a partir de los años veinte de los denominados autores galantes intermedios.

Claramente reconocible como pliego amatorio prototípico del periodo postincunable es el encabezado por una composición de cierta amplitud -un decir generalmente- que actúa como reclamo editorial, siendo Garci Sánchez de Badajoz el autor ligado por antonomasia a estos cuadernos, si bien la supervivencia del poeta en el medio a lo largo de toda la primera mitad del s. XVI -fundamentalmente- se producirá a través de piezas menores como villancicos, canciones o algún «romance»-perqué en realidad-, siempre en posición de interior de impreso, lo que denunciaría, además del lugar más común para esas composiciones menores, el desplazamiento editorial conocido por Badajoz, en función, a todas luces, de modas a las que parece que no es ajeno el entramado de la Literatura Popular Impresa. Incuestionable resulta, por otra parte, que serán los géneros situados en la parte más baja del registro cortés los que habrán de tener una penetración más profunda y duradera en el ámbito, siendo paradigmático de ello la difusión en pliegos de un Juan del Encina, el autor cancioneril de mayor presencia en él a lo largo de la centuria, cuyos villancicos, con continuidad nada desdeñable en la segunda mitad de siglo y con frecuencia de una forma anónima que da cuenta de su grado de popularización, constituyen ya lo más característico de la obra amatoria del salmantino en cuadernos postincunables.

Si bien unas y otras figuras llegan a convivir en el medio, a partir de la tercera década de siglo el testigo de esos autores cancioneriles es tomado en gran medida por la categoría autorial correspondiente a los poetas galantes intermedios, es decir, poetas al margen de los grandes cancioneros, pero que 
siguen su estética para la creación de unas piezas amorosas que combinan, generalmente, con glosas de romances y, en menor medida, con versos burlescos. A través de ellos se produce la asimilación plena del Cancionero por la Literatura Popular Impresa, circunstancia que hemos podido comprobar meridianamente mediante el estudio de la obra de un Alonso de Salaya. El análisis detenido de su producción no deja duda alguna sobre cómo se produce la apropiación popular del Cancionero: en la línea de las composiciones más perdurables de Sánchez de Badajoz y de Encina, son piezas amorosas menores, comenzando por canciones y villancicos, las que se vinculan con Salaya en una tipología de pliegos muy idiosincrática e íntimamente conectada con estos autores galantes intermedios, aquella en la que la glosa de romances se muestra como encabezamiento y reclamo editorial, con continuidad todavía en la segunda mitad del s. XVI. Junto con esa presencia de canciones y villancicos y su función más o menos complementaria dentro del cuaderno, el análisis de la poesía amorosa de Salaya en concreto nos muestra, a la par, la centralidad en ella de otro género situado en el nivel bajo del registro cortés, el del romance: de él ofrece el autor varios ejemplos con un formato compositivo muy similar sustentado sobre el conocido ejercicio cancioneril de expresión de la fenomenología del amor a través de personificaciones alegóricas que, de alguna manera, toma el testigo del amplio decir alegórico-amoroso del que todavía hallamos ecos en pliegos postincunables.

Solo nos queda insistir, para terminar, en que son estos autores galantes intermedios los que filtran en su dimensión más profunda la popularización del Cancionero; autores que, frente a los «préstamos» de obras procedentes de las grandes figuras cancioneriles, configuran ya dentro del ámbito de la Literatura Popular Impresa una tradición propia de nombres y textos, la misma que se inserta medularmente en el encuentro entre la «alta» y «baja» cultura sobre la que esta habrá de despegar.

Recibido: $14 / 03 / 2020$

Aceptado: 30/04/2020 


\section{$\cos$}

LA POPULARIZACIÓN DEL CANCIONERO:

DE LOS GRANDES POETAS CANCIONERILES A LOS AUTORES GALANTES INTERMEDIOS

(CON un estudio de Caso: Alonso de Salaya)

RESUMEN: Este artículo analiza el proceso de apropiación de la poesía de Cancionero por el ámbito de la Literatura Popular Impresa a través de su temática más idiosincrática, la amorosa. Para ello, atendemos a la difusión en pliegos poéticos tanto de los grandes nombres de Cancionero como de los poetas categorizados por la crítica reciente como «autores galantes intermedios». Presentamos un estudio de caso de esta última categoría autorial: Alonso de Salaya.

Palabras clave: Poesía de Cancionero. Pliegos poéticos. Siglo XVI. Garci Sánchez de Badajoz. Juan del Encina. Autores galantes intermedios. Alonso de Salaya.

THE CANCIONERO POPULARIZATION:

FROM THE GREAT CANCIONERO POETS TO THE AUTORES GALANTES INTERMEDIOS

(WITH a CASE STUdy: Alonso de SAlaya)

ABSTRACT: This paper analyzes the process of assimilation of the «Cancionero» poetry by the field of the Printed Popular Literature by focusing on its most idiosyncratic subject matter: love poems. To achieve this purpose, we deal with the diffusion in Spanish poetic chapbooks of the great names of «Cancionero», as well as of the poets that have been characterized as «autores galantes intermedios» by the recent critics. We provide a case study of the aforementioned authorial category: Alonso de Salaya.

KeYwords: Cancionero poetry. Spanish poetic chapbooks. 16th century. Garci Sánchez de Badajoz. Juan del Encina. «Autores galantes intermedios». Alonso de Salaya. 